\title{
Morphology and developmental traits of the trilobite Changaspis elongata from the Cambrian Series 2 of Guizhou, South China
}

Guang-Ying Du, Jin Peng, De-Zhi Wang, Qiu-Jun Wang, Yi-Fan Wang, and Hui Zhang Acta Palaeontologica Polonica 64 (4), 2019: 797-813 doi:https://doi.org/10.4202/app.00604.2019

The morphology and ontogeny of the trilobite Changaspis elongata based on 216 specimens collected from the Lazizhai section of the Balang Formation (Stage 4, Series 2 of the Cambrian) in Guizhou Province, South China are described. The relatively continuous ontogenetic series reveals morphological changes, and shows that the species has seventeen thoracic segments in the holaspid period, instead of the sixteen as previously suggested. The development of the pygidial segments shows that their number gradually decreases during ontogeny. A new dataset of well-preserved specimens offers a unique opportunity to investigate developmental traits after segment addition is completed. The ontogenetic size progressions for the lengths of cephalon and trunk show overall compliance with Dyar's rule. As a result of different average growth rates for the lengths of cephalon, trunk and pygidium, the length of the thorax relative to the body shows a gradually increasing trend; however, the cephalon and pygidium follow the opposite trend. Morphometric analysis across fourteen post-embryonic stages reveals growth gradients with increasing values for each thoracic segment from anterior to posterior. The reconstruction of the development traits shows visualization of the changes in relative growth and segmentation for the different body parts. The new dataset and growth gradient of the trunk suggest that the thoracic segment growth dynamics of early Cambrian to Silurian trilobites follow the same general continuous, steady-state growth gradient decreasing from posterior to anterior.

Key words: Trilobita, Oryctocephalinae, Changaspis, developmental traits, ontogeny, Cambrian, China.

Guang-Ying Du [544840279@qq.com], College of Resource and Environment Engineering, Guizhou University, 2708 South Section of Huaxi Avenue, Guiyang, 550025, China; and College of Information Engineering, Guizhou University of Traditional Chinese Medicine, Dongqing South Road, Guiyang, 550025, China. Jin Peng [gzpengjin@126.com] (corresponding author), De-Zhi Wang [1440823413@qq.com ], Qiu-Jun Wang [18785177085@qq.com], Yi Fan Wang [256797947@qq.com], and Hui Zhang [724291335@qq.com], College of Resource and Environment Engineering, Guizhou University, 2708 South Section of Huaxi Avenue, Guiyang, 550025, China. 
This is an open-access article distributed under the terms of the Creative Commons

Attribution License (for details please see creativecommons.org), which permits unrestricted use, distribution, and reproduction in any medium, provided the original author and source are credited.

\author{
FoF Full text $(1,777.1 \mathrm{kB})$ । \\ Forif Supplementary file $(102.4 \mathrm{kB})$
}

